Supporting Information for

\title{
Surface Electronic Modulation with Hetero-Single Atoms to Enhance Oxygen Evolution Catalysis
}

Feng Li, ${ }^{1}$ Gao-Feng Han, ${ }^{1 *}$ Jong-Pil Jeon, ${ }^{1}$ Tae Joo Shin, ${ }^{3}$ Zhengping Fu, ${ }^{2 *}$ Yalin Lu, ${ }^{2}$ JongBeom Baek $^{1 *}$

${ }^{1}$ School of Energy and Chemical Engineering/Center for Dimension-Controllable Organic Frameworks, Ulsan National Institute of Science and Technology (UNIST), 50 UNIST, Ulsan 44919, South Korea

${ }^{2}$ Anhui Laboratory of Advanced Photon Science and Technology, Hefei National Laboratory for Physical Sciences at Microscale, University of Science and Technology of China (USTC), 96 Jinzhai, Hefei, Anhui 230026, P. R. China

${ }^{3}$ UNIST Central Research Facilities, Ulsan National Institute of Science and Technology (UNIST), 50 UNIST, Ulsan 44919, South Korea

* To whom correspondence should be addressed. E-mail: jbbaek@unist.ac.kr, fuzp@ustc.edu.cn, gfhan@unist.ac.kr. 


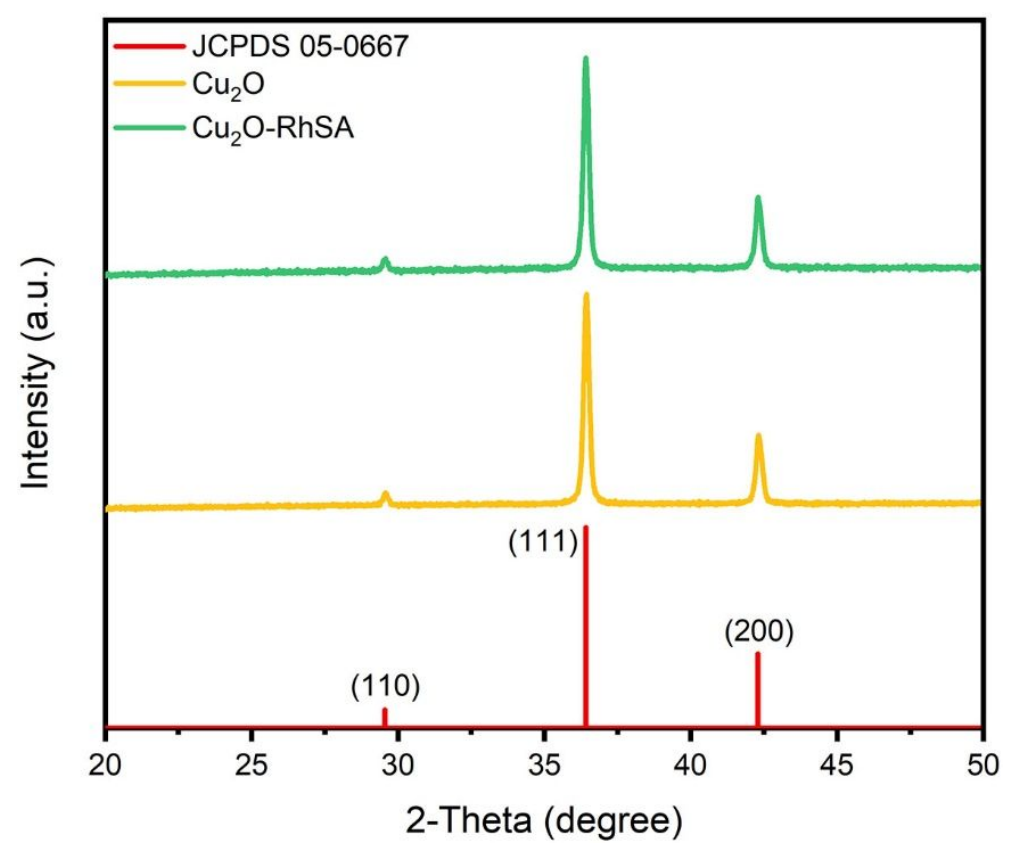

Figure S1. XRD patterns of $\mathrm{Cu}_{2} \mathrm{O}$ and $\mathrm{Cu}_{2} \mathrm{O}-\mathrm{RhSA}$, respectively, as well as the reference JCPDS 05-0667. Compared with $\mathrm{Cu}_{2} \mathrm{O}$, no additional XRD peak was observed in $\mathrm{Cu}_{2} \mathrm{O}-\mathrm{RhSA}$. 


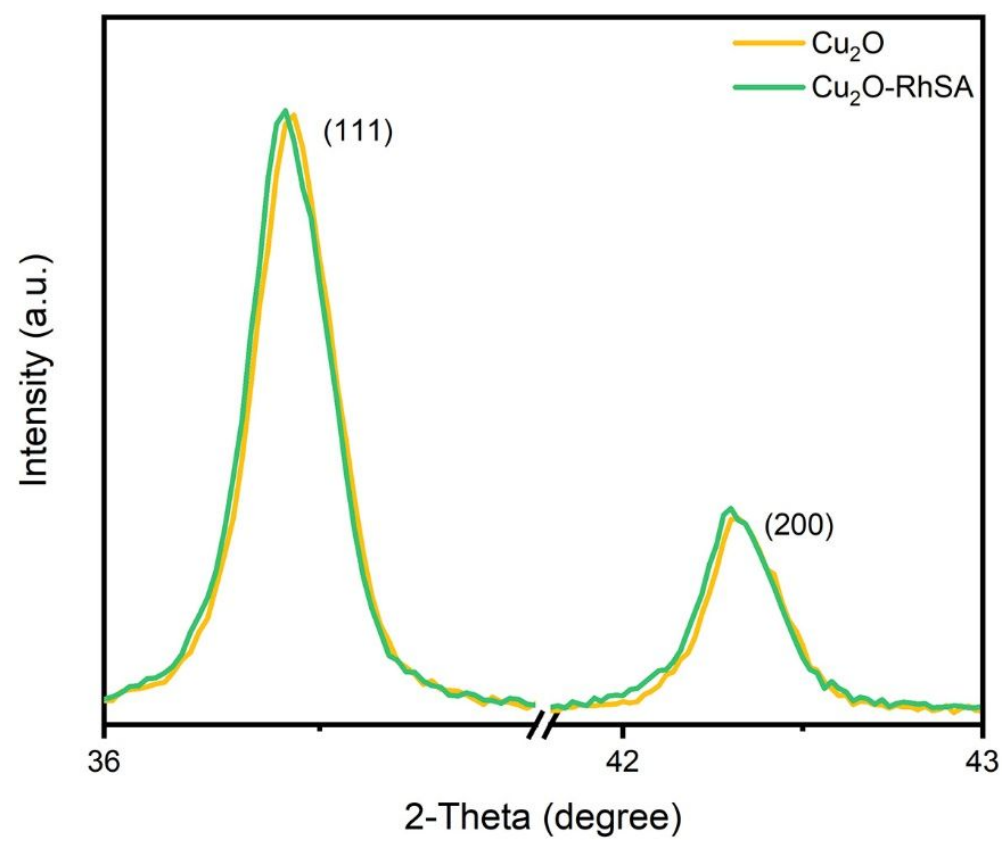

Figure S2. Comparison of the XRD patterns of $\mathrm{Cu}_{2} \mathrm{O}$ and $\mathrm{Cu}_{2} \mathrm{O}-\mathrm{RhSA}$ in the selected region.

The peaks for $\mathrm{Cu}_{2} \mathrm{O}-\mathrm{RhSA}$ exhibited a slight shift towards a lower angle, compared with $\mathrm{Cu}_{2} \mathrm{O}$.

The slight difference between the peak shapes of the $\mathrm{Cu}_{2} \mathrm{O}$ and $\mathrm{Cu}_{2} \mathrm{O}-\mathrm{RhSA}$ can be attributed to the core-shell structure of the $\mathrm{Cu}_{2} \mathrm{O}-\mathrm{RhSA}$.
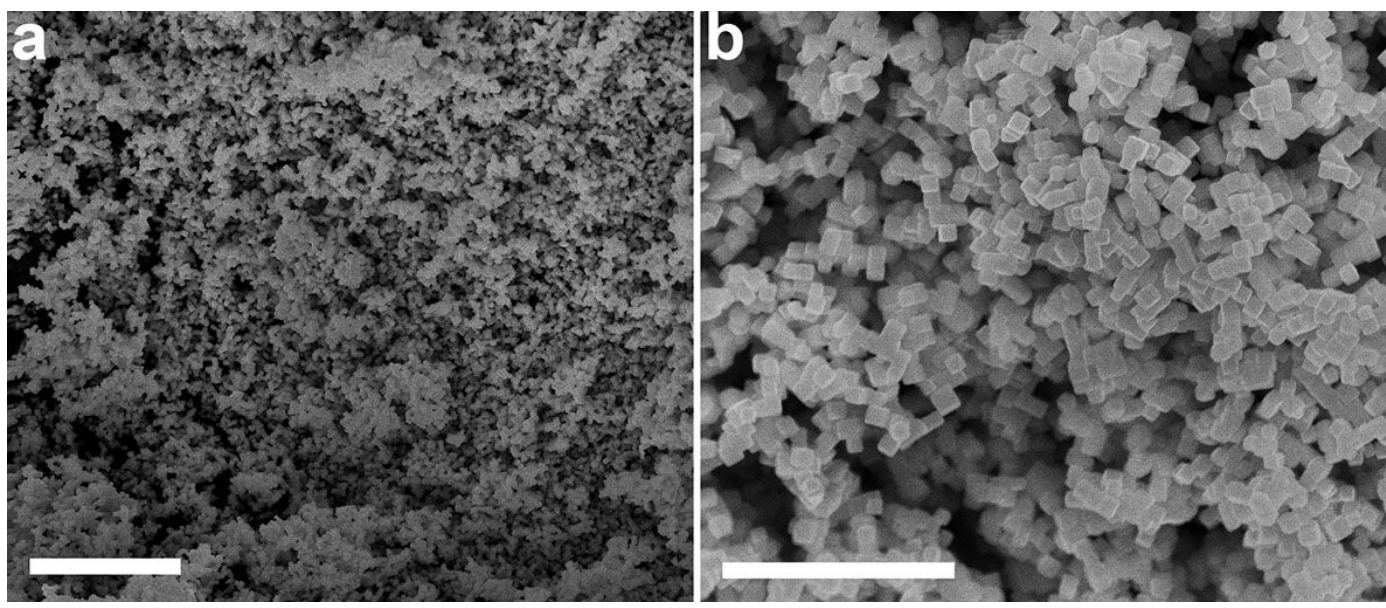

Figure S3. a-b, Low and high-resolution FE-SEM images of pristine $\mathrm{Cu}_{2} \mathrm{O}$ nanocubes, respectively. Scale bar: a, $5 \mu \mathrm{m} ; \mathbf{b}, 2 \mu \mathrm{m}$. 


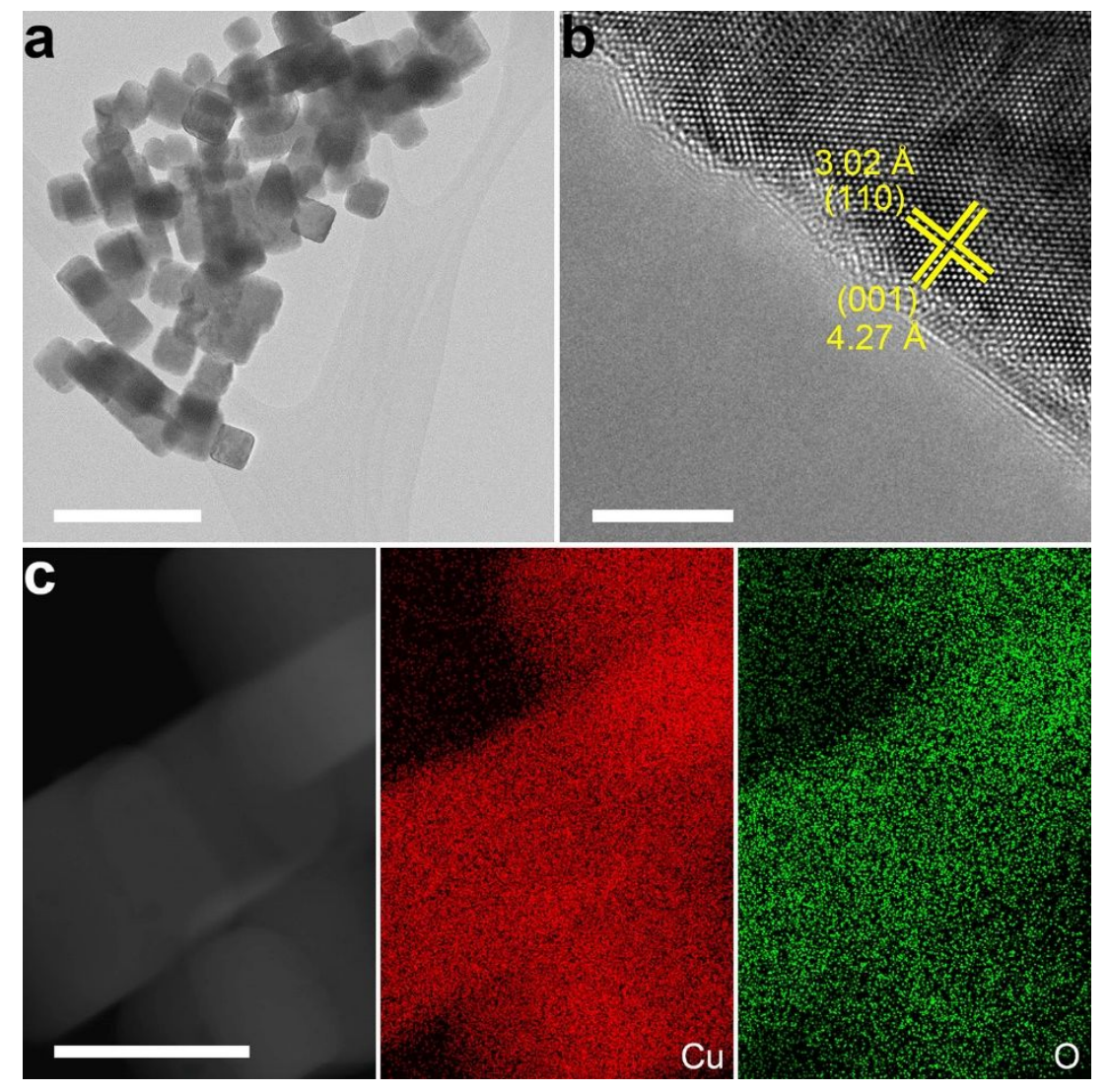

Figure S4. a, Low-resolution TEM image of $\mathrm{Cu}_{2} \mathrm{O}$ nanocubes. b, High-resolution TEM image of the edge of a $\mathrm{Cu}_{2} \mathrm{O}$ nanocube. The beam diffraction direction is the $<110>$ zone axis. $\mathbf{c}$, Element mapping images of $\mathrm{Cu}_{2} \mathrm{O}$ nanocubes. Scale bar: a, $400 \mathrm{~nm} ; \mathbf{b}, 5 \mathrm{~nm}$;, $100 \mathrm{~nm}$. 

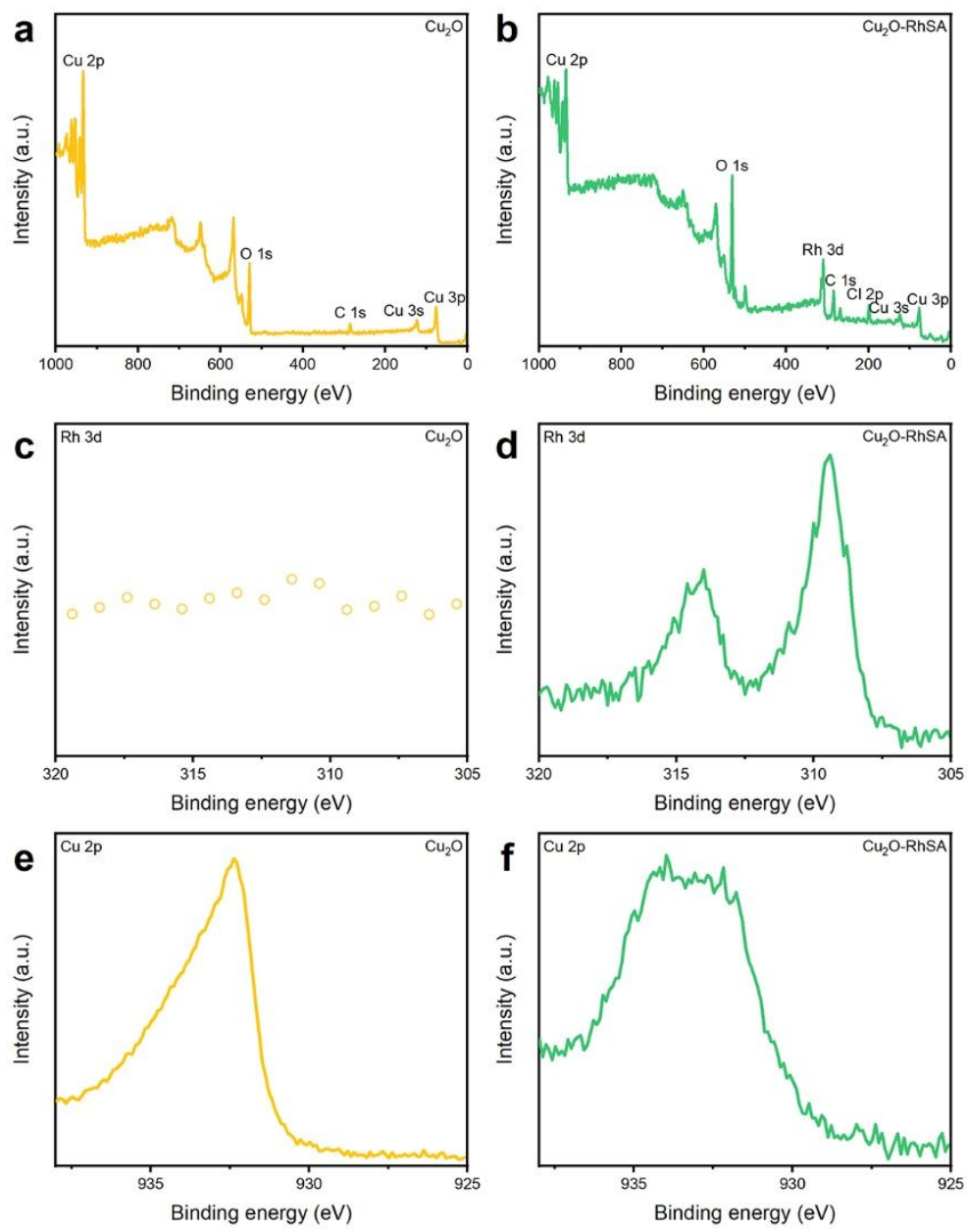

Figure S5. a-b, Full survey XPS spectrum of $\mathrm{Cu}_{2} \mathrm{O}$ and $\mathrm{Cu}_{2} \mathrm{O}-\mathrm{RhSA}$. c-d, High-resolution $\mathrm{Rh}$ $3 \mathrm{~d}$ XPS spectrum of $\mathrm{Cu}_{2} \mathrm{O}$ and $\mathrm{Cu}_{2} \mathrm{O}-\mathrm{RhSA}$. e-f, High-resolution $\mathrm{Cu} 2 \mathrm{p}$ XPS spectrum of $\mathrm{Cu}_{2} \mathrm{O}$ and $\mathrm{Cu}_{2} \mathrm{O}-\mathrm{RhSA}$. 

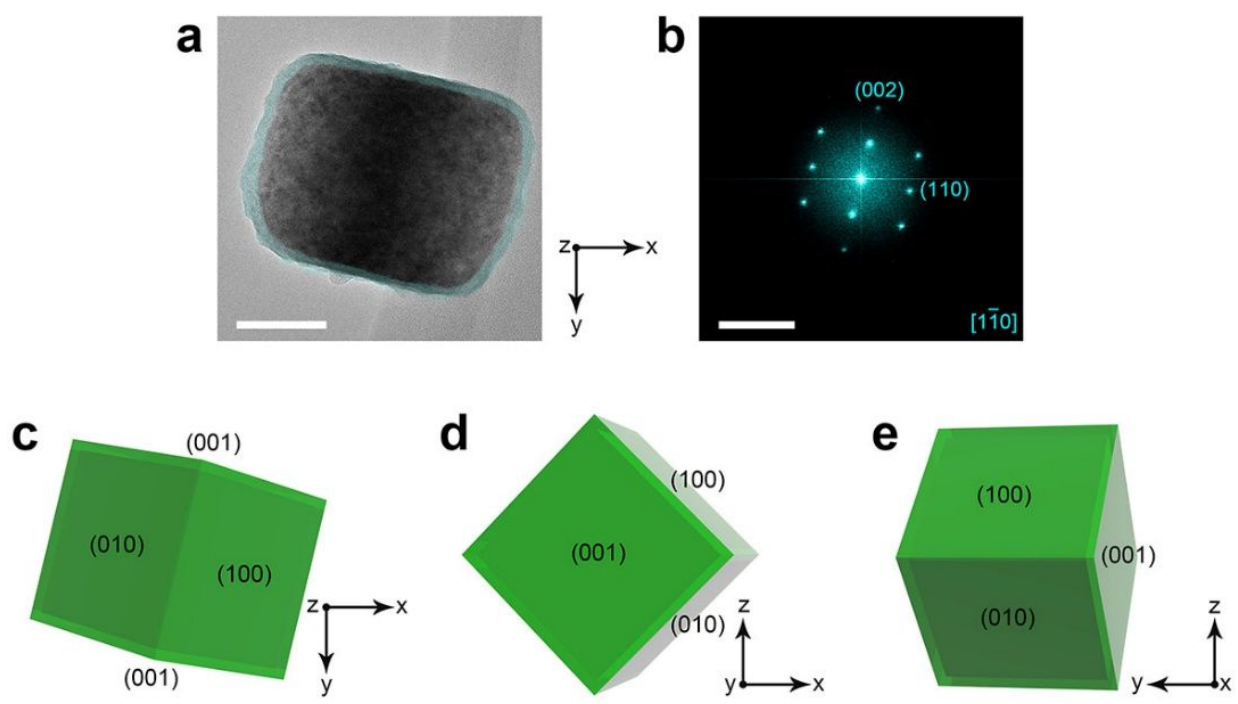

Figure S6. a, Low-resolution TEM image of a $\mathrm{Cu}_{2} \mathrm{O}-\mathrm{RhSA}$ nanocube. b, Fast Fourier transformation (FFT) pattern of the core of a $\mathrm{Cu}_{2} \mathrm{O}-\mathrm{RhSA}$ nanocube. The beam diffraction direction is the $<110>$ zone axis. c-e, Three-dimensional schematic visualization of the $\mathrm{Cu}_{2} \mathrm{O}$ RhSA nanocube in a from different views. Scale bar: a, $40 \mathrm{~nm} ; \mathbf{b}, 5 \mathrm{~nm}^{-1}$. 

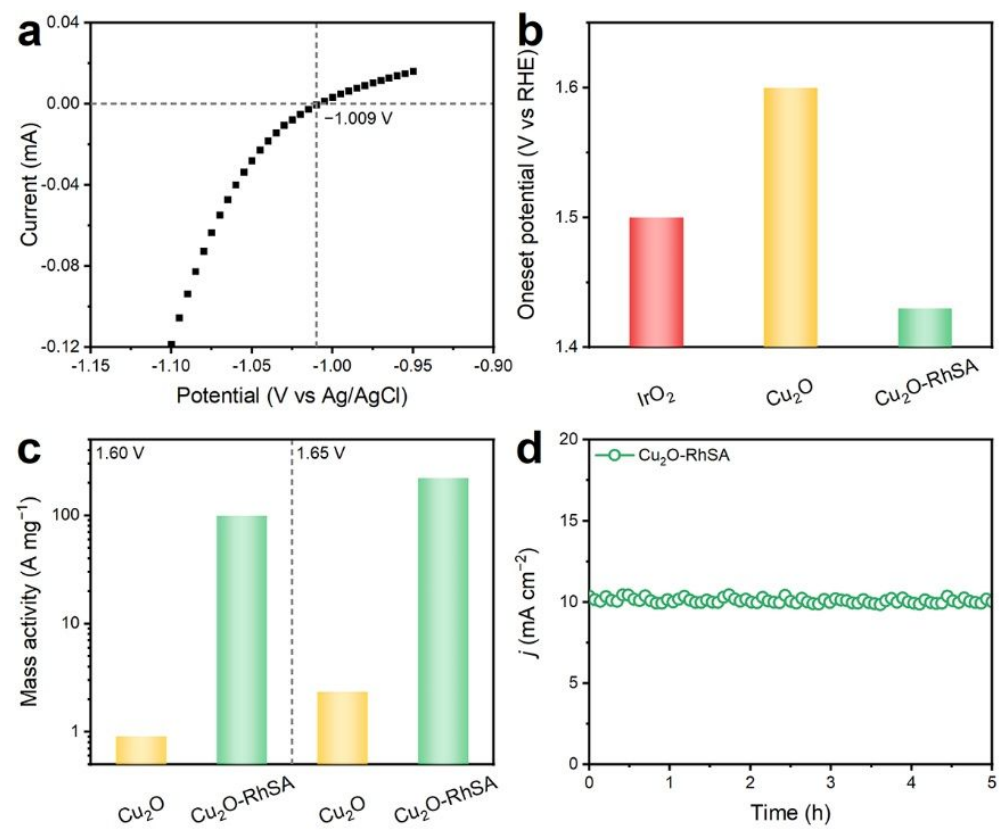

Figure S7. a, Calibration of the $\mathrm{Ag} / \mathrm{AgCl}$ electrode with respect to $\mathrm{RHE}$, using the polarization curve of Pt black in highly pure $\mathrm{H}_{2}$ saturated $1.0 \mathrm{M}$ aq. $\mathrm{KOH}$ solution. b, The onset potentials for $\mathrm{IrO}_{2}, \mathrm{Cu}_{2} \mathrm{O}$ and $\mathrm{Cu}_{2} \mathrm{O}-\mathrm{RhSA}$, respectively. c, The mass activities for $\mathrm{Cu}_{2} \mathrm{O}$ and $\mathrm{Cu}_{2} \mathrm{O}-\mathrm{RhSA}$ at different potentials. d, Chronoamperometric test at a constant potential. 

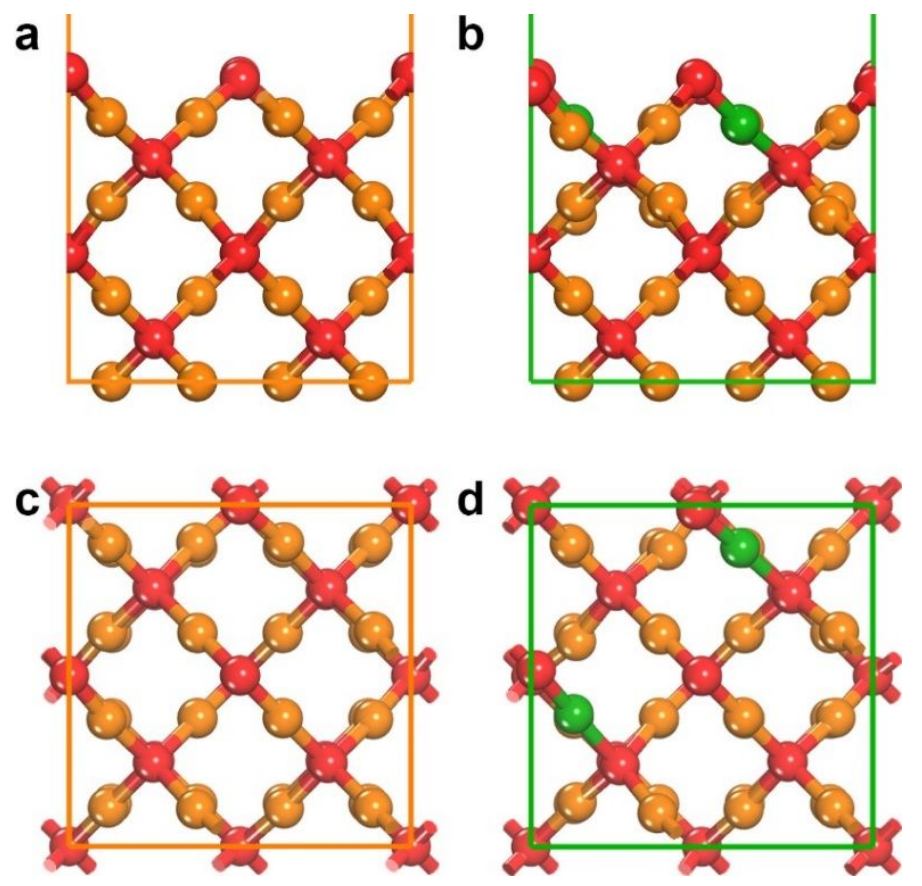

Figure S8. a, b, Side-view of the optimized structures of $\mathrm{Cu}_{2} \mathrm{O}$ and $\mathrm{Cu}_{2} \mathrm{O}-\mathrm{RhSA}$, respectively. c, $\mathbf{d}$, Top-view of the optimized structures of $\mathrm{Cu}_{2} \mathrm{O}$ and $\mathrm{Cu}_{2} \mathrm{O}-\mathrm{RhSA}$, respectively. The orange, green and red balls are copper, rhodium and oxygen atoms, respectively.
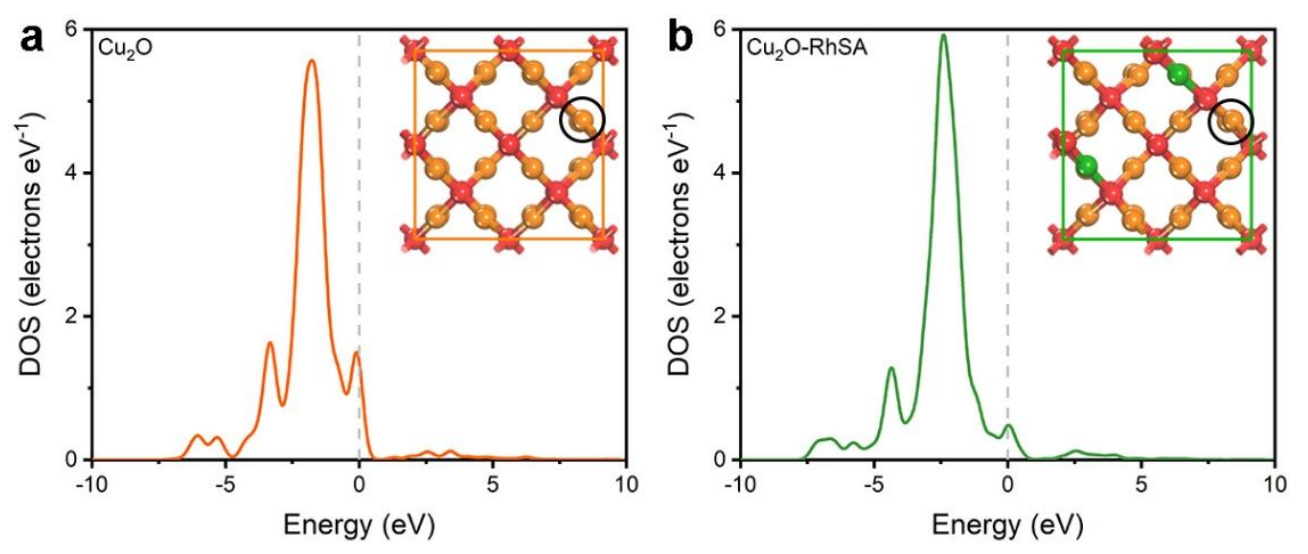

Figure S9. a, b, The projected density of states (DOS) distribution of surface $\mathrm{Cu}$ sites (marked with circles in the insets) in $\mathrm{Cu}_{2} \mathrm{O}$ and $\mathrm{Cu}_{2} \mathrm{O}-\mathrm{RhSA}$, respectively. The first peak on the $d$-band of $\mathrm{Cu}$ shifted to higher energy level after Rh migration. The orange, green and red balls are copper, rhodium and oxygen atoms, respectively. 
a

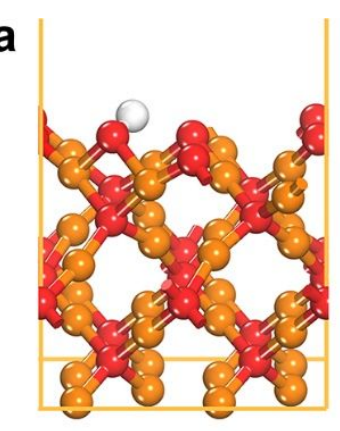

b
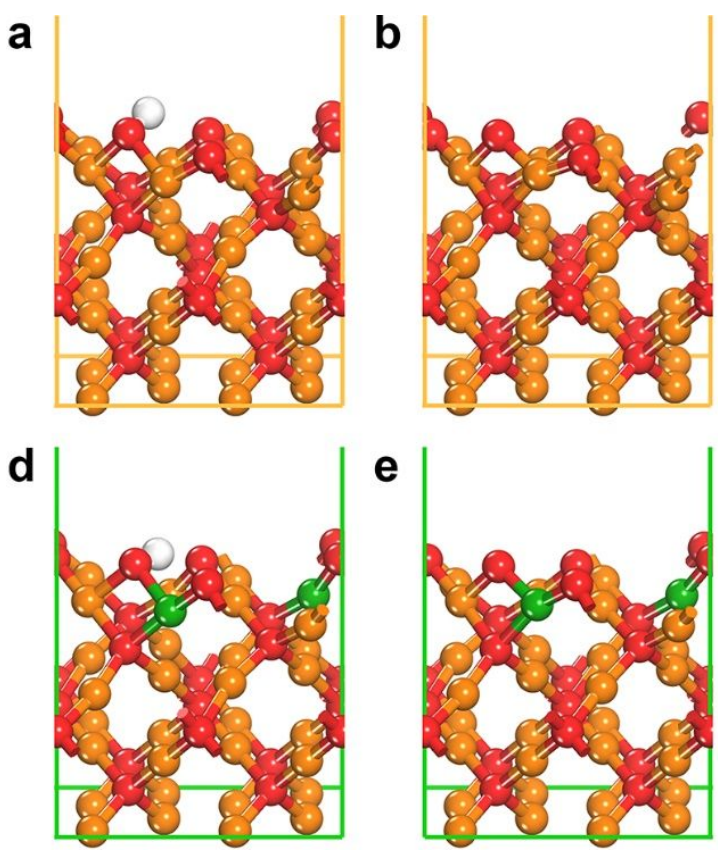

e

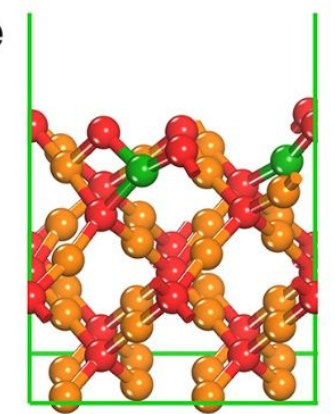

C
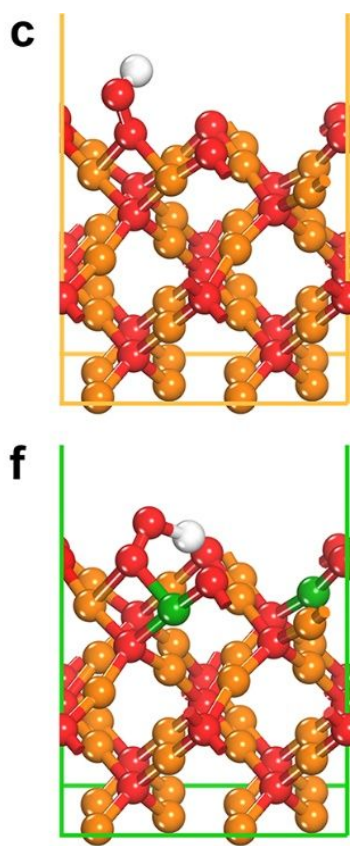

Figure S10. a-c, Optimized structures of $\mathrm{Cu}_{2} \mathrm{O}$ adsorbed with $\mathrm{OH}, \mathrm{O}$ and $\mathrm{OOH}$ reaction intermediates, respectively. d-f, Optimized structures of $\mathrm{Cu}_{2} \mathrm{O}-\mathrm{RhSA}$ adsorbed with $\mathrm{OH}, \mathrm{O}$ and $\mathrm{OOH}$ reaction intermediates, respectively. The orange, green, red and white balls are copper, rhodium, oxygen and hydrogen atoms, respectively. 

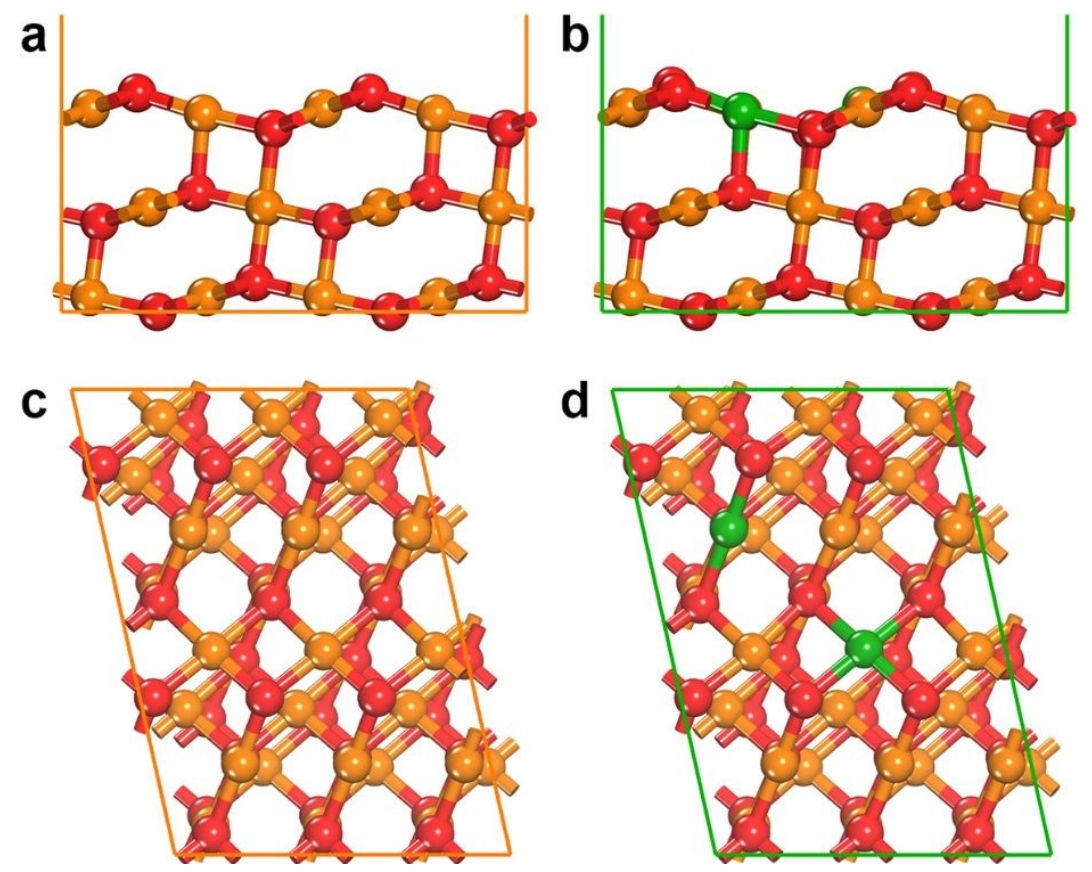

Figure S11. a, b, Side-view of the optimized structures of $\mathrm{CuO}(111)$ planes without/with $\mathrm{Rh}$ SAs (denoted as $\mathrm{CuO} / \mathrm{CuO}-\mathrm{RhSA}$ ), respectively. $\mathbf{c}, \mathbf{d}$, Top-view of the optimized structures of $\mathrm{CuO} / \mathrm{CuO}-\mathrm{RhSA}$, respectively. The orange, green and red balls are copper, rhodium and oxygen atoms, respectively. 
a

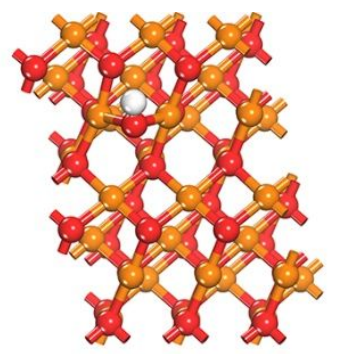

d

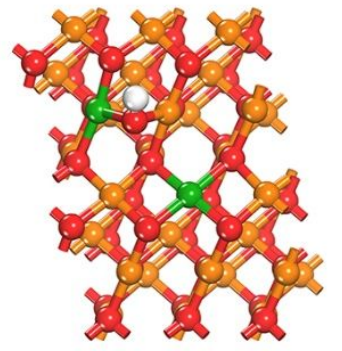

b

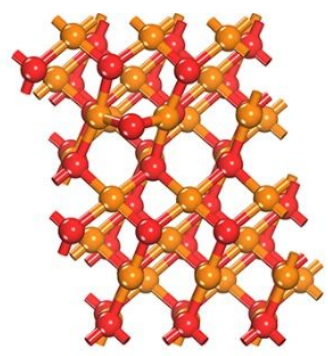

e

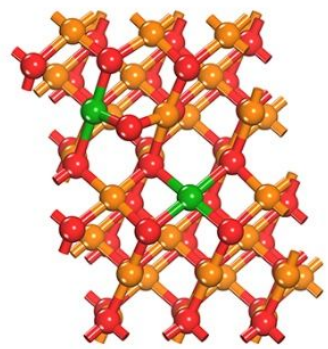

C

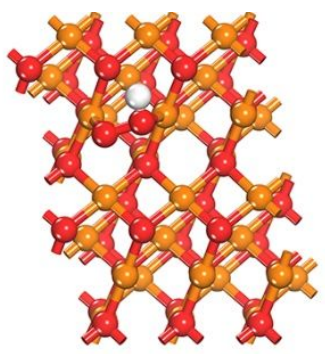

f

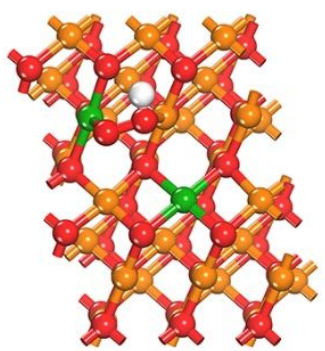

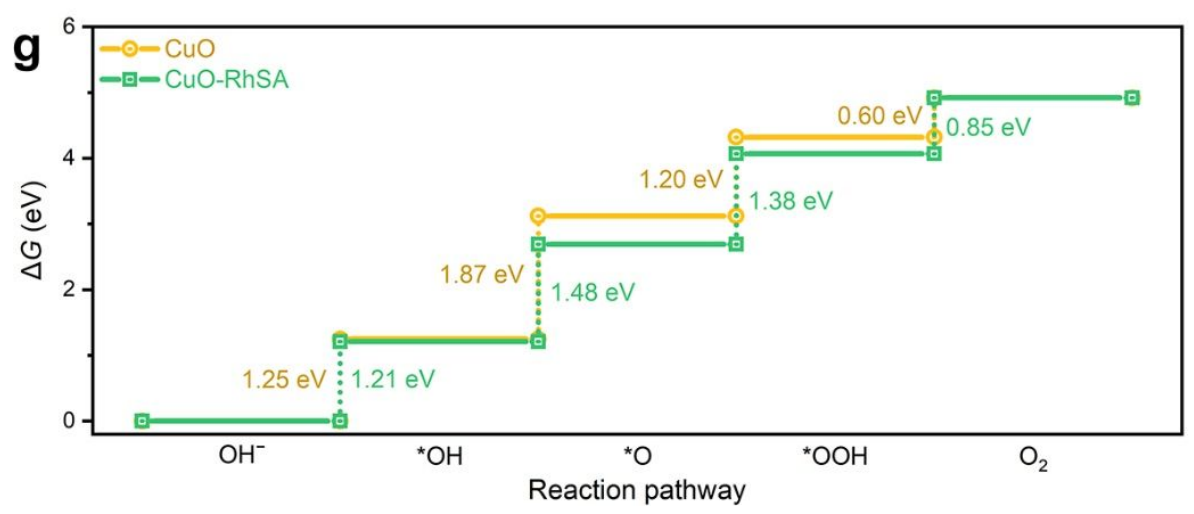

Figure S12. a-c, Top-view of optimized structures of $\mathrm{CuO}$ adsorbed with $\mathrm{OH}, \mathrm{O}$ and $\mathrm{OOH}$ reaction intermediates, respectively. d-f, Top-view of optimized structures of $\mathrm{CuO}-\mathrm{RhSA}$ adsorbed with $\mathrm{OH}, \mathrm{O}$ and $\mathrm{OOH}$ reaction intermediates, respectively. g, Free energy diagrams along the OER reaction pathway on the active sites of $\mathrm{CuO}$ and $\mathrm{CuO}-\mathrm{RhSA}$, respectively. The orange, green, red and white balls are copper, rhodium, oxygen and hydrogen atoms, respectively. 
Table S1. OER parameters of recently reported outstanding catalysts in alkaline electrolyte

\begin{tabular}{|c|c|c|c|}
\hline Catalyst & $\begin{array}{c}\text { Overpotential @ } 10 \\
\mathbf{m A ~ c m} \mathbf{c m}^{-2}(\mathbf{m V})\end{array}$ & $\begin{array}{l}\text { Tafel slope } \\
\left(\mathrm{mV} \mathrm{dec}^{-1}\right)\end{array}$ & Reference \\
\hline $\mathrm{Cu}_{2} \mathrm{O}-\mathrm{RhSA}$ & 308 & 49 & This work \\
\hline $\mathrm{Cu}_{2} \mathrm{O}$ nanocubes & 542 & 120 & This work \\
\hline SC CoO NRs & 330 & 44 & $\begin{array}{c}\text { Nat. Commun. 2016, } 7, \\
12876 .\end{array}$ \\
\hline $\mathrm{Co} @ \mathrm{Co}_{3} \mathrm{O}_{4} / \mathrm{NC}-2$ & 390 & 54.3 & $\begin{array}{l}\text { Angew. Chem. Int. Ed. } \\
\text { 2016, 55, } 4087 .\end{array}$ \\
\hline $\mathrm{Co}_{2} \mathrm{Mo}_{3} \mathrm{O}_{8} @ \mathrm{NC-800}$ & 331 & 87.5 & $\begin{array}{c}\text { Angew. Chem. Int. Ed. } \\
2020,59,11948\end{array}$ \\
\hline $\mathrm{Ba}_{4} \mathrm{Sr}_{4}\left(\mathrm{Co}_{0.8} \mathrm{Fe}_{0.2}\right)_{4} \mathrm{O}_{15}$ & 340 & 47 & $\begin{array}{l}\text { Adv. Mater. 2020, 32, } \\
1905025\end{array}$ \\
\hline $\mathrm{LaCoO}_{3}$ & 490 & 79 & $\begin{array}{l}\text { Nat. Commun. } \\
2016,7,11510\end{array}$ \\
\hline$p$-SnNiFe & 350 & 35 & $\begin{array}{c}\text { Nat. Commun. } \\
2017,8,394\end{array}$ \\
\hline $\mathrm{CoSe}_{0.85}$ & 324 & 85 & $\begin{array}{l}\text { Adv. Mater. 2016, 28, } \\
77\end{array}$ \\
\hline CoMnP & 330 & 61 & $\begin{array}{c}\text { J. Am. Chem. Soc. 2016, } \\
\text { 138, } 4006\end{array}$ \\
\hline $\mathrm{Co}_{2} \mathbf{P}$ & 370 & 128 & $\begin{array}{c}\text { J. Am. Chem. Soc. 2016, } \\
138,4006\end{array}$ \\
\hline $\mathrm{NiCoP} / \mathrm{C}$ & 330 & 96 & $\begin{array}{c}\text { Angew. Chem. Int. Ed., } \\
\text { 2017, 129, } 3955\end{array}$ \\
\hline $\mathrm{Co}_{3} \mathrm{O}_{4} / \mathrm{NGPC}$ & 420 & -- & $\begin{array}{l}\text { Angew. Chem. Int. Ed. } \\
\text { 2016, 55, } 4977\end{array}$ \\
\hline $\operatorname{NiCo}(O H)_{x}$ & 410 & 65 & $\begin{array}{c}\text { Adv. Energy Mater. } \\
2015,5,1401880\end{array}$ \\
\hline
\end{tabular}

